\title{
Water safety training as a potential means of reducing risk of young children's drowning
}

\author{
Kenneth N Asher, Frederick P Rivara, Deborah Felix, Linley Vance, Rosemary Dunne
}

\begin{abstract}
Objectives-To determine the effects of training in swimming and water safety on young preschool children's ability to recover safely from a simulated episode of falling into a swimming pool.

Design-Randomized trial of 12 or eight weeks' duration water safety and swimming lessons for children 24 to 42 months old.

Outcome measures-Swimming ability, deck behavior, water recovery, and swimming to side after jumping into pool were measured before, during, and after the training program.
\end{abstract}

Results-109 children completed the study (61 in the 12 week group, 48 in the eight week group). The average age was 34.2 months, $54 \%$ were male. Swimming ability, deck behavior, water recovery, and jump and swim skills improved over baseline levels in both groups. By the end of training, the 12 week group improved more than the eight week group only in swimming ability. Improvements in water recovery and jump and swim skills were associated positively with changes in swimming ability.

Conclusions-Swimming ability and safety skills of young preschool children can be improved through training. Such programs may offer some protection for children at risk of drowning and there was no indication that this program increased the risk of drowning. However, pool fencing, other barriers around water, and parental supervision still remain the most important prevention strategies to reduce drowning in young children.

(Injury Prevention 1995; 1: 228-233)

Harborview Injur Research Center, Departments of Pediatrics and Epidemiology,

University of

Washington and

Children's Hospital

Medical Center,

Seattle, Washington,

USA

KN Asher

FP Rivara

D Felix

L Vance

R Dunne

Correspondence and requests for reprints to:

Dr KN Asher, Harborview Injury Prevention and

Research Center, 325 Ninth

Avenue, ZX-10, Seattle, WA 98104, USA. sequelae in survivors, with nearly all who require cardiopulmonary resuscitation dying or being left with severe brain injury. Thus, primary prevention remains the most effective tactic to significantly reduce the risk of mortality and serious morbidity from drowning.

To address this problem, passive approaches such as four sided fencing with self latching gates have received attention..$^{5}$ Despite their proven effectiveness and their attractiveness as passive prevention strategies, these have not been widely adopted in the United States. ${ }^{1}$ Another popular but unproved prevention strategy is teaching swimming and water safety skills to young children. This has been vigorously promoted by the Red Cross, the YMCA, and other organizations, and widely publicized by the mass media. Nevertheless, its effectiveness in reducing mortality or morbidity has not been adequately evaluated. ${ }^{78}$ Some experts have even raised concerns that swimming lessons may increase the risk of drowning by lessening toddlers' fear of the water and creating a false sense of security in parents. ${ }^{9}$ Adverse effects of swimming on infants and toddlers have been reported, including water intoxication ${ }^{10}$ and various infectious diseases. ${ }^{11}$ For these reasons, many organizations (including the American Academy of Pediatrics) have hesitated to support water safety and swimming lessons for young children.

The purpose of this study is to begin to investigate the possibility of reducing preschool children's risk of drowning by providing training in swimming skills and water safety. It is not feasible to conduct a prospective trial with decreased drowning episodes as an outcome. The annual rate of drowning in this age group is approximately six per $100000 .^{6}$ Thus, over one million children would have to be studied to observe a $50 \%$ risk reduction. An increase in water safety skills, and recovery from a simulated episode of falling into a pool are, therefore, used as a proxy for decreased drowning risk.

The study was based upon the following hypotheses. First, swimming ability would be positively related to the degree of participation in the training program. Second, children with water safety training would exhibit safer behavior at the poolside than children with less training. Third, children with more training would act more competently in simulated high risk situations than children with less training. Fourth, children's swimming ability would be positively related to their water safety behavior. Fifth, children's developmental and behavioral characteristics would have independent effects on water safety behavior before training, and on changes due to instruction.

\section{Subjects and methods}

\section{SUBJECTS}

This study population consisted of children between 24 and 42 months of age at entry into the study. Children and families were recruited 
by letters at the child care centers and follow up telephone calls over an 18 month period from middle income Seattle area child care centers near public pools chosen for the study. We felt that families with more limited resources would have difficulty coming to all the training and testing sessions. Children were only accepted if they had no prior swimming training and no chronic medical or developmental disability, based on parents' completion of the revised Denver Prescreening Developmental Questionnaire. ${ }^{12}$ Participants received $\$ 50$ upon completion of the last measures. This study was approved by the human subjects review committees of Children's Hospital and Medical Center and the University of Washington.

\section{DESIGN}

The study used a randomized design with repeated measures at four times (see figure). Children were randomly assigned to either 12 weeks or eight weeks of twice weekly swimming and water safety instruction. To be included in the analysis at the conclusion of the study, children in the 12 week group had to have missed no more than five of the 24 lessons given, and children in the eight week group had to have missed no more than three of their 16 lessons. The sample size was based on practical considerations of funds available and on sample size estimates giving a power of $80 \%$ to detect a $20 \%$ difference in skill level before and after training.

Water safety skills were initially measured in both groups at time 1 (T1) and the swimming ability of the 12 week group was also assessed at this time. Training in the eight week group was delayed by eight weeks (from the initial observation time) to allow for assessment of the effect of the study instruments themselves on children's water safety and behavior. After eight weeks of training for the 12 week group, and eight weeks of no training for the eight week group, water safety skills were again measured at time 2 (T2). Swimming ability of both groups was again assessed. After four more weeks of training for the 12 weeks group, and eight weeks for the eight week group, water safety skills and swimming ability were measured in both groups at time 3 (T3, note that T3 was four weeks earlier for the 12 week than for the eight week group). A final measurement of water safety skills was conducted 12 weeks after the end of the training in both

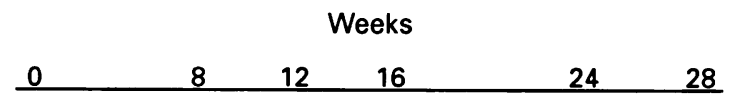

Assignment

12 week course

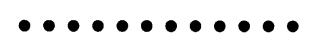

T1

T2 T3

T4

8 week course

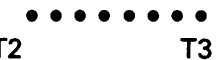

T3

T4

Research design. Training periods are indicated by filled cricles, measurement times by ' $T$ '. groups at time 4 (T4). No attempt was made to control the amount of time spent in the water other than during the intervention.

\section{WATER SAFETY TRAINING PROGRAM}

All children participated in biweekly water safety and swimming lessons. The curriculum was designed for preschool age children, based upon the American Red Cross program..$^{13-15}$ It emphasized three sets of skills: (1) out-of-water safety behavior ('deck behavior'); (2) swimming ability; and (3) in-water safety skills. Instruction was provided in groups of approximately six children, accompanied in the pool by their parents. Instructors were trained by the Children's Hospital and Medical Center swimming program director, who made random checks of the quality of instruction in approximately $10 \%$ of the lessons throughout the study.

\section{MEASURES}

Study measurements and their scheduled administration times are shown in table 1.

Demographic and general child behavior information

A number of child and family variables were assessed. At T1, parents were asked to provide educational and occupational information on themselves and their spouse/partners (A Hollingshead, Department of Sociology, Yale University, 1975; unpublished). They completed the general development scale of the Minnesota Child Development Inventory (MCDI) to estimate their children's developmental levels, ${ }^{16}$ and the Achenbach 2-3 year Child Behavior Checklist (CBCL) to measure behavioral concerns. ${ }^{17} 18$

\section{Swimming ability}

Using a structured grading scheme based upon that developed by Erbaugh, ${ }^{1920}$ instructors rated swimming ability. In this system, in which higher scores indicated greater ability, children were tested at $\mathrm{T} 1, \mathrm{~T} 2$, and $\mathrm{T} 3$ for the 12 week group, and at T2 and T 3 for the eight week group. Examples of the skills rated included holding their face in water for three seconds, recovering from prone position, rolling back-to-front, propulsive kicking, beginner stroke for five feet, independently entering and exiting pool, and jumping into the pool independently.

\section{Water safety skills}

Children's water safety skills were measured in three ways by direct observation. (1) Deck behavior consisted of six items of children's behavior around the pool deck that would increase the risk of drowning: for example, running around pool edge, pushing other children, and getting into water without an adult. These behaviors were each assessed both while the children were clothed and in their swimsuits. Deck behavior was scored during the few minutes before the actual swimming lessons began, with higher scores indicating riskier 
Table 1 Data collected and measurement times

\begin{tabular}{lllll}
\hline & \multicolumn{3}{c}{ Measurement time } \\
\cline { 2 - 6 } Measure & $T 1$ & $T 2$ & $T 3$ & $T 4$ \\
\hline $\begin{array}{l}\text { Demographic and general child } \\
\text { behavior information }\end{array}$ & & & & \\
$\quad$ Parents' education and occupation & $\times$ & & & \\
MCDI & $\times$ & & & \\
CBCL & $\times$ & & & \\
Swimming ability in each group & & & & \\
12 week & $\times$ & $\times$ & $\times$ & \\
8 week & & $\times$ & $\times$ & \\
Water safety skills & & & & \\
Deck behavior & $\times$ & $\times$ & $\times$ & $\times$ \\
Water recovery & $\times$ & $\times$ & $\times$ & $\times$ \\
Jump and swim & $\times$ & $\times$ & $\times$ & $\times$ \\
\hline
\end{tabular}

behavior. (2) Water recovery, that is the ability to recover and stand up when dropped from two feet above the water (which was at the shallow end of the pool two feet deep), was assessed, first, with the instructor releasing the child, and if the child resisted, with the parent releasing the child. If the child resisted release from two feet above the water, the adult would attempt release from the water's surface. (3) Jump and swim, that is the ability to jump from edge of pool into the pool and swim back to the side. The child was initially asked to do this by the observer, if the child refused the observer, the child was then asked to jump by the parent. If the child resisted jumping from the side, she or he was released by the adult in the pool to swim to the side. The child was not required to climb out of the pool. Water recovery and jump and swim were ordinally rated from the less difficult challenges to the more difficult as described above, with higher scores indicating greater skill. Independent observers blind to children's group assignments conducted all observations and ratings, with frequent random reliability checks by the research coordinator. All were assessed at T1, T2, T3, and T4.

\section{DATA ANALYSIS}

Repeated measures analysis of variance was used to assess the effects of the intervention, as well as of duration of training. T1 measures were compared with $\mathrm{T} 4$, and the differences

Table 2 Characteristics of participating children and families at beginning and end of water safety training

\begin{tabular}{|c|c|c|c|}
\hline & \multicolumn{2}{|l|}{ Group } & \multirow[b]{2}{*}{ Total } \\
\hline & 12 week & 8 week & \\
\hline $\begin{array}{l}\text { Baseline assessment (T1) } \\
\text { No } \\
\text { Male (\%) } \\
\text { Mean (SD) age in months } \\
\text { SES }(\% \text { at level)^ }\end{array}$ & $\begin{array}{l}91 \\
50 \\
33 \cdot 0(5 \cdot 6)\end{array}$ & $\begin{array}{l}71 \\
54 \\
33 \cdot 4(5 \cdot 6)\end{array}$ & $\begin{array}{l}162 \\
53 \\
34 \cdot 1(5 \cdot 6)\end{array}$ \\
\hline 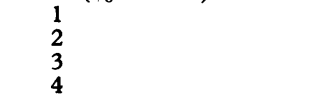 & $\begin{array}{l}23 \\
36 \\
30 \\
11\end{array}$ & $\begin{array}{r}37 \\
36 \\
23 \\
4\end{array}$ & $\begin{array}{r}31 \\
36 \\
26 \\
8\end{array}$ \\
\hline $\begin{array}{l}\text { Final assessment (T4) } \\
\text { No } \\
\text { Male }(\%) \\
\text { Mean }(\mathrm{SD}) \text { age in months } \\
\text { SES }(\% \text { at level })^{\star}\end{array}$ & $\begin{array}{l}61 \\
52 \\
34 \cdot 6(5 \cdot 5)\end{array}$ & $\begin{array}{l}48 \\
56 \\
33 \cdot 6(5 \cdot 6)\end{array}$ & $\begin{array}{l}109 \\
54 \\
34 \cdot 2(5 \cdot 5)\end{array}$ \\
\hline $\begin{array}{l}1 \\
2 \\
3 \\
4\end{array}$ & $\begin{array}{r}21 \\
39 \\
33 \\
7\end{array}$ & $\begin{array}{r}42 \\
33 \\
23 \\
2\end{array}$ & $\begin{array}{r}30 \\
37 \\
28 \\
5\end{array}$ \\
\hline
\end{tabular}

SES = socioeconomic status. between the eight week and 12 week groups were compared at T1, T2, T3, T4.

\section{Results}

STUDY STAMPLE

At the beginning of the study (T1), 162 children were enrolled:91 randomly assigned to the 12 week group and 71 to the eight week group. Although equal numbers of children were initially assigned to the two groups, there was drop out before the study began at T1. This differential early drop out continued throughout the study, precluding equal group sizes, and was probably related to the extra measurement session in the eight week group before swimming lessons began. Even so, the two groups did not differ significantly on age or gender. About $67 \%$ of the sample fell in the two highest categories of socioeconomic status; although somewhat fewer families in the 12 week group were in the highest category, the difference in these proportions was not significant (see table 2).

By the end of the study 109 children had met all of the criteria for inclusion in the analyses. Their mean (SD) age was $34 \cdot 2$ (5.5) months, with boys comprising $54 \%$ of the sample. As at $\mathrm{T} 1$, the two groups did not differ significantly in these characteristics. As before, despite apparent under-representation of 12 week group families in the highest category of socioeconomic status compared with the eight week group, the difference did not reach significance. There were no differences between the 109 children who completed the study and the 53 children who dropped out on gender, age distribution, socioeconomic status, or baseline skills in water safety, deck behavior, or water recovery. Reasons for drop out were primarily inability to come to training and/or testing sessions.

\section{WATER SAFETY OUTCOME MEASURES Swimming ability}

Both groups showed highly significant improvements in swimming ability during the eight weeks after the beginning of training (T1-T2 for the 12 week group, T2-T3 for the eight week group) (Wilk's $\lambda$ multivariate $F(1$, $49)=141.00, \mathrm{p}<0.0001)$. This improvement continued to week 12 (that is, T3) (Wilk's $\lambda$ multivariate $F(1,51)=164 \cdot 71, \mathrm{p}<0.0001)$. The eight week group was significantly superior to the 12 week group at the first lesson (T1 for the 12 week group, T2 for the eight week), and at eight weeks (T2 for the 12 week group, T3 for the eight week), but not when compared with the 12 week group's final ability. However, the two groups' improvement over time did not differ significantly from one another (table 3 ). These changes from before to after training represent improvements in skill from being able to only bob in the water initially to being able to kick propulsively by the end of training.

Deck behavior

Deck behavior varied significantly from $T 1$ through $\mathrm{T} 4$, only because of a significant 
Table 3 Ratings of swimming ability before and during water safety training

\begin{tabular}{|c|c|c|c|}
\hline & \multicolumn{2}{|c|}{ Mean $(S D)$ score $^{\star}$} & \multirow{2}{*}{$\begin{array}{l}12 \text { week } \mathrm{v} 8 \text { week } \\
\text { comparison p value }\end{array}$} \\
\hline & 12 week group & 8 week group & \\
\hline $\begin{array}{l}\text { Before } \\
\text { At } 8 \text { weeks of training }\end{array}$ & $\begin{array}{l}2 \cdot 63(2 \cdot 55) \\
7 \cdot 28(4 \cdot 27)\end{array}$ & $\begin{array}{l}4.48(3.01) \\
8.85(3.78)\end{array}$ & $\begin{array}{l}0.03 \\
0.006\end{array}$ \\
\hline \multicolumn{4}{|c|}{ Wilk's $\lambda F(1,49)=141.00, p<0.0001$ for changes over first 8 weeks ${ }^{\star}$ of training } \\
\hline At 12 weeks of training & $9.45(4.09)$ & - & $0.60 \dagger$ \\
\hline
\end{tabular}

* Possible range $=0-15$, with higher scores indicating better ability. +Comparison of final assessment in each group

improvement at T4 (multivariate $\mathrm{F}$ (3, $45)=3.17, \quad \mathrm{p}<0.03)$. There were no significant differences between the 12 week and eight week groups (table 4).

\section{Water recovery}

With training, water recovery scores improved steadily and significantly in both groups (multivariate $F(3,43)=33.70, p<0.0001$ for change over time). The 12 week group improved immediately (from $\mathrm{T} 1$ to $\mathrm{T} 2$ - the beginning of their training period), and continued to do so through T4. The eight week group also made significant improvement between $\mathrm{T} 2$ and $\mathrm{T} 3$ (their training period) so at the end of the training there was no significant difference between the two groups (table 5).

Fump and swim

As with the water recovery scores, jump and swim scores improved over time (multivariate $\mathrm{F}(3,41)=5.07, \mathrm{p}<0.005)$, with the 12 week group's improvement slightly, but nonsignificantly, greater than the eight week's (table 6).

Table 4 Ratings of deck behavior before, during, and after water safety training

\begin{tabular}{|c|c|c|c|}
\hline & \multicolumn{2}{|c|}{ Mean $(S D)$ score ${ }^{\star}$} & \multirow{2}{*}{$\begin{array}{l}12 \text { week } \mathrm{v} 8 \text { week } \\
\text { comparison p value }\end{array}$} \\
\hline & 12 week group & 8 week group & \\
\hline $\begin{array}{l}\text { T1 } \\
\text { T2 } \\
\text { T3 } \\
\text { T4 }\end{array}$ & $\begin{array}{l}2.34(2.37) \\
2.02(1.89) \\
2.55(2.29) \\
1.79(2.03)\end{array}$ & $\begin{array}{l}2 \cdot 10(2 \cdot 31) \\
2 \cdot 35(2 \cdot 64) \\
2 \cdot 29(2 \cdot 50) \\
1.66(2 \cdot 07)\end{array}$ & $\begin{array}{l}0.98 \\
0.32 \\
0.96 \\
0.74\end{array}$ \\
\hline \multicolumn{4}{|c|}{ Wilk's $\lambda F(3,45)=3.17, p<0.03$ for $\mathrm{T} 1-\mathrm{T} 4$ changes } \\
\hline
\end{tabular}

^Possible range $=1-12$, with higher scores indicating riskier behavior.

Table 5 Ratings of water recovery before, during, and after water safety training

\begin{tabular}{|c|c|c|c|}
\hline & \multicolumn{2}{|c|}{ Mean (SD) score } & \multirow{2}{*}{$\begin{array}{l}12 \text { week } \mathrm{v} 8 \text { week } \\
\text { comparison p value }\end{array}$} \\
\hline & 12 week group & 8 week group & \\
\hline \multirow[t]{2}{*}{$\begin{array}{l}\text { T1 } \\
\text { T2 } \\
\text { T3 } \\
\text { T4 }\end{array}$} & $\begin{array}{l}5.43(1.32) \\
7.74(3.00) \\
9.29(3.02) \\
9.54(2.77)\end{array}$ & $\begin{array}{l}5.83(1.34) \\
6.29(2.06) \\
9.28(3.05) \\
8.36(2.62)\end{array}$ & $\begin{array}{l}0.06 \\
0.01 \\
0.26 \\
0.26\end{array}$ \\
\hline & \multicolumn{3}{|c|}{ Wilk's $\lambda F(3,43)=33.70, p<0.001$ for $T 1-T 4$ changes } \\
\hline
\end{tabular}

$\star$ Possible range $=1-12$, with higher scores indicating better skills.

Table 6 Ratings of jump and swim ability before, during, and after water safety training

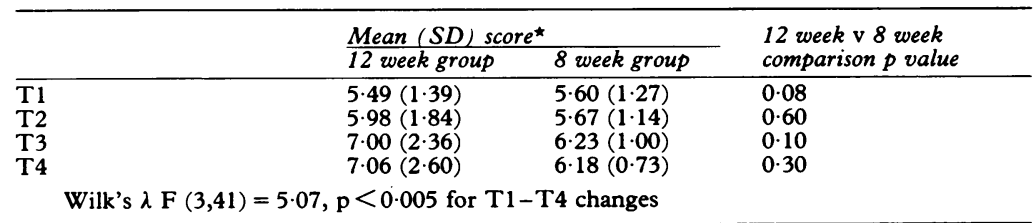

*Possible range $=1-12$, with higher scores indicating better skills.
RELATIONSHIP OF SWIMMING ABILITY WITH WATER SAFETY SKILLS

Swimming ability was not significantly correlated with deck behavior, water recovery, and jump and swim scores for either the 12 week or the eight week groups at the beginning of training. Likewise, swimming ability was not significantly correlated with deck behavior at the last lesson for either group (end of 12th week, end of eighth week, respectively), but was moderately correlated at the last lesson with water recovery scores $(r=0.54$, $\mathrm{p}<0.0001$ for the 12 week group, $r=0.51$, $\mathrm{p}<0.0003$ for the eight week group) and with the 12 week group's jump and swim scores $(r=0.72, \mathrm{p}<0.0001)$.

RELATIONSHIP OF DEVELOPMENTAL AND BEHAVIORAL CHARACTERISTICS WITH SWIMMING ABILITY AND WATER SAFETY SKILLS

Small, positive correlations (that is, in the $0 \cdot 2$ to 0.3 range) were found between chronological age, MCDI developmental age, and MCDI developmental quotient, and swimming ability, deck behavior, water recovery, and jump and swim. In general, older children (chronologically and developmentally) had better water recovery and jump and swim scores at T2 and T3. However, none of the correlations between the developmental variables and the outcome variables at $\mathrm{T} 4$ were significant. Gender and CBCL score were not significantly related to any of the outcome variables.

\section{Discussion}

In this study of 109 young preschool age children, instruction in swimming and water safety significantly improved swimming ability. It also improved two measures of in-water safety skills that attempted to simulate drowning risk. In contrast, out-of-water safety skills showed minimal improvement. The greatest changes took place during the first eight weeks of instruction, although some improvements continued for children receiving a four further weeks of training. Improvement was stronger, and appeared sooner, for water recovery skills than for jump and swim skills. Water safety behavior was strongly related to swimming ability after eight weeks' training. This improvement in water safety skills was not only statistically significant but also reflected real changes in abilities. The swimming skills acquired, and the increased ability to recover from a fall into a pool, represent potentially lifesaving skills.

While this study provided one of the few direct tests of the benefits of water safety instruction for young preschool age children, it has several limitations. First, it used simulated risk as a proxy for drowning and near drowning. A cohort study or experiment with submersion incidents as the outcome was not feasible and would not be ethically acceptable. We believed that the proxy used was a reasonable simulation of a young child falling into a pool. Because of safety concerns in the 
study, we did not assess the impact of the intervention on more realistic drowning scenarios, for example, falling into and getting out of a pool without an adult present. We also do not know how well our tests measured the ability of a child to avoid or survive a real submersion episode. There was no way to 'validate' these measures further.

Second, the comparison group (eight week) received training as well as the full treatment group (12 week), diminishing the possible differences between the two conditions. This comparison group allowed us to test the short term changes in swimming skills without an intervention, as well as any possible effect of the testing procedures themselves on skills. In addition, it would have been difficult to recruit subjects without offering any training. The two groups were similar demographically, although the eight week group had a somewhat higher, but non-significant, proportion of families at the highest socioeconomic level. The two groups were similar at baseline in their deck behavior, water recovery, and jump and swim scores - our major outcome measures. However, the eight week group had higher swimming ability at initial assessment than did the 12 week group. The reasons for this are unknown, but as safety skills and swimming ability were unrelated at baseline, the effect on the outcome should be small.

Third, the study sample was self selected (that is, parents volunteered their children), and thus were more likely to have some interest in water safety. The effects of this on the children's performance is unknown. The children participating in the study were mostly from middle and upper income families. The response of children from poorer and less educated families to the intervention is unknown, limiting generalizability of the results. There were somewhat more families in the highest socioeconomic strata in the eight week group. However, there were no differences in the proportion of children in the two lowest strata, in which one might expect to see some effect on the intervention. The duration of the swimming lessons of eight to 12 weeks may also limit the generalizability of the study results, as such lessons may not be available to some families. Future studies should examine the effectiveness of fewer lessons and shorter intervention on swimming skills and water safety.

Fourth, the artificiality of the study setting (that is, participating in a research and training study, and receiving payment) may have affected the behavior of the children and their parents, although the children's age would lessen this effect.

Fifth, the relatively short duration of children's involvement in the study limited our ability to assess how long the effect persists, especially if it is not reinforced.

Finally, the study did not attempt to measure any potential negative effects of the intervention, such as an over confidence on the part of children and/or their parents after the training. Some injury prevention strategies have proved potentially harmful, such as the effect of drivers' education which lowered driving age and increased the number of motor vehicle crashes in young drivers. ${ }^{21}$ These potential negative effects are important to evaluate and should be examined in future, larger studies of water safety training.

This study should be viewed as an exploratory effort to provide information on the effectiveness of water safety training. The ability to fully test the intervention with a large scale experiment using submersion or drowning as an outcome is limited, given the relative rarity of these events. Such an evaluation will require quasiexperimental methods, such as a case-control study in which the exposure of interest is prior water safety training.

Despite the above limitations, the results of this study offer several implications for parents and others interested in the safety of young children around water. First, water safety is not a simple entity. Different aspects are affected by training in different ways, for example, deck behavior did not improve significantly, despite the improvement in in-water safety skills. While water safety training for young preschool age children may reduce their risk of drowning, it does not have a similar effect on their poolside behavior, and thus their risk of falling in. Finally, while there was no support for the concern that water safety instruction increases young children's risk of drowning, their improved skills do not reduce the need for adult monitoring, supervision, and safety awareness. The potential impact of such a program on decreasing parental vigilance must be further assessed, because vigilance is a crucial element in any drowning prevention program.

\section{IMPLICATIONS FOR PREVENTION}

We believe that the results of this study show that there are potential benefits for young preschool age children in learning swimming and water safety skills. This study should be repeated by others; if the results are replicated, swimming and water safety training should be promoted as part of a drowning prevention program for this age range. However, a comprehensive approach would incorporate passive protection, such as water barriers and personal flotation devices, active measures such as water safety and swimming instruction, and parental awareness and supervision. All such elements should be advocated strongly to optimize water safety and enjoyment for young children.

This work was supported by Maternal and Child Health Research Grant No MCJ-530607, from the Maternal and Child Health Bureau of the United States Department of Health and Human Services.

Great appreciation is expressed to the children and their parents who participated in this study, the swimming instrucparents who participated in this study, the swimming instruc-
tors from Seattle Children's Hospital and Medical Center, and Robert Soderberg, who provided analytic assistance with a maximum of energy and minimum of exasperation.

1 Baker SP, O'Neill B, Ginsburg MJ, Li G. The injury fact book. 2nd Ed. New York: Oxford University Press, 1992. 2 O'Carroll PW, Alkon E, Weiss B. Drowning mortality in Los Angeles County, 1976 to 1984. $¥ A M A$ 1988; 260: 380-3. 
3 Quan L, Gore EJ, Wentz K, Allen J, Novack AH. Ten-year study of pediatric drownings and near-drownings in King County, Washington: lessons in injury prevention. Pediatrics 1989; 83: 1035-40.

4 Washington State Injury Prevention Program. Drowning in Washington State. Olympia, WA: Washington State Department of Health, 1991.

5 Wintemute GJ. Childhood drowning and near-drowning in the United States. Am F Dis Child 1990; 144: 663-9.

6 Wintemute GJ, Kraus JF, Teret SP, Wright M. Drowning in childhood and adolescence: a population-based study. Am $\exists$ Public Health 1987; 77: 830-2.

7 Rivara FP. Traumatic deaths of children in the United States: currently available prevention strategies. PediatStates: currently availa
rics $1985 ; 75: 456-62$.

8 Diamond EF. Swimming instruction for preschool children. Sports Med 1975; 3: 58-60.

9 Committee on Pediatric Aspects of Physical Fitness, Recreation, and Sports. Swimming instructions for infants. Pediatrics 1980; 65: 847

10 Wright $M$, deSilva $P$, Sinha $S$. Hyponatraemia in children. BMF 1992; 305: 51-2.

11 Mahoney FJ, Farley TA, Kelso KY, Wilson SA, Horan JM, McFarland LM. An outbreak of hepatitis A associated with swimming in a public pool. F Infect Dis 1992; 165: 613-8.

12 Frankenburg WK, Fandal AW, Thornton SM. Revision of the Denver Prescreening Developmental Questionnaire.
Pediatr 1987; 110: 653-7.

3 The American National Red Cross. Swimming and aquatics safety. Washington, DC: American National Red Cross, 1981 .

14 The American National Red Cross. American Red Cross water safety instructor's manual. St Louis, MO: Mosby Year Book, 1992.

15 American National Red Cross. Swimming and diving. St Louis, MO: Mosby - Year Book, 1992.

16 Ireton J, Thwing E. The Minnesota Child Development Inventory. Minneapolis, MN: Behavioral Science Systems, 1974.

17 Achenbach TM, Edelbrock C, Howell CT. Empiricallybased assessment of the behavioral/emotional problems of 2-3-year-old children. $₹$ Abnorm Child Psychol 1987; 15: 2-3-year $629-50$.

18 McConaughy SH, Achenbach TM. Practical guide for the Child Behavior Checklist and related materials. Burlington, VT: University of Vermont, 1988.

19 Erbaugh SJ. Assessment of swimming performance of preschool children. Percept Mot Skills 1978; 47: 1179-82.

20 Erbaugh SJ. Effects of aquatic training on swimming skill development of preschool children. Percept Mot Skills 1986; 62: 439-46.

21 Robertson LS. Crash involvement of teenaged drivers when driver education is eliminated from high school. $\mathrm{Am} \mathcal{F}$ Public Health 1980; 70: 599-603.

\section{'Transport minister needs head examined over helmet use'}

This was the headline used for a letter I wrote to our local paper complaining about the transport minister's reasons for not wishing to introduce helmet legislation. His explanation was the old chestnut: you can't pass a law (or enforce one) until some mythical proportion of the population is already, in effect, in compliance. (I wish I knew where this came from). Although I think my letter was a good one, it was greatly enhanced by one that appeared below it from a parent describing how her 10 year old was rendered unconscious after colliding with a car. The helmet was 'smashed in on one side from the impact ...' - ample testimony to the force absorbed. Interestingly, she concluded by stating her belief in how important it is for parents to set a good example, and asserting that she always wears a helmet.

\section{More on bike helmets}

A columnist in the Globe and Mail (which describes itself as Canada's national newspaper) wrote a piece with the title 'Why helmet laws treat adults like children'. His arguments were simply incredible (literally so). Apart from a raft of irrelevant and misleading statistics, he agued that 'The costs of mandatory helmets is measured not only in dollars but in lives. The added nuisance of finding and wearing a helmet will cause a certain number of bike trips to be replaced with car trips; . . . That means moe chance of auto accidents, and fewer health benefits from cycling'. I am simply unable to follow this logic. Can anyone help? (Globe and Mail, June 21, 1995.)

Tales of an inept bikeriding editor

After finally deciding to replace my old and beloved bike helmet with a lighter, more jazzy one, I find myself quite unable to figure out how to adjust the straps to ensure a proper fit. Does anyone have any SIMPLE advice that an aging bicyclist is likely to understand? 